Article

\title{
Lactobacillus reuteri I5007 Modulates Intestinal Host Defense Peptide Expression in the Model of IPEC-J2 Cells and Neonatal Piglets
}

\author{
Hongbin Liu ${ }^{1, \dagger}$, Chengli Hou ${ }^{1,2,+}$, Gang Wang ${ }^{1}$, Hongmin Jia ${ }^{1}$, Haitao Yu ${ }^{1}$, Xiangfang Zeng ${ }^{1}$, \\ Philip A. Thacker ${ }^{3}$, Guolong Zhang ${ }^{4}$ and Shiyan Qiao ${ }^{1, *}$ \\ 1 State Key Laboratory of Animal Nutrition, China Agricultural University, Beijing 100193, China; \\ binhongliu@126.com (H.L.); houchengli@163.com (C.H.); crazygang@126.com (G.W.); \\ jiahongmin@126.com (H.J.); 15600660793@163.com (H.Y.); ziyangzxf@163.com (X.Z.) \\ 2 Institute of Food Science and Technology CAAS, Chinese Academy of Agricultural Sciences, \\ Beijing 100193, China \\ 3 Department of Animal and Poultry Science, University of Saskatchewan, Saskatoon, SK S7N 5C5, Canada; \\ phil.thacker@usask.ca \\ 4 Department of Animal Science, Oklahoma State University, Stillwater, OK 74074, USA; \\ glenn.zhang@okstate.edu \\ * Correspondence: qiaoshy@mafic.ac.cn; Tel.: +86-10-6273-1456 \\ + These authors contributed equally to this work.
}

Received: 22 April 2017; Accepted: 26 May 2017; Published: 31 May 2017

\begin{abstract}
Modulation of the synthesis of endogenous host defense peptides (HDPs) by probiotics represents a novel antimicrobial approach for disease control and prevention, particularly against antibiotic-resistant infections in human and animals. However, the extent of HDP modulation by probiotics is species dependent and strain specific. In the present study, The porcine small intestinal epithelial cell line (IPEC-J2) cells and neonatal piglets were used as in-vitro and in-vivo models to test whether Lactobacillus reuteri 15007 could modulate intestinal HDP expression. Gene expressions of HDPs, toll-like receptors, and fatty acid receptors were determined, as well as colonic short chain fatty acid concentrations and microbiota. Exposure to $10^{8}$ colony forming units (CFU)/mL of L. reuteri 5007 for $6 \mathrm{~h}$ significantly increased the expression of porcine $\beta$-Defensin2 (PBD2), pBD3, pBD114, pBD129, and protegrins (PG) 1-5 in IPEC-J2 cells. Similarly, L. reuteri I5007 administration significantly increased the expression of jejunal pBD2 as well as colonic pBD2, pBD3, pBD114, and pBD129 in neonatal piglets $(p<0.05)$. This was probably associated with the increase in colonic butyric acid concentration and up-regulating expression of Peroxisome Proliferator-Activated Receptor- $\gamma$ (PPAR- $\gamma$ ) and G Protein-Coupled Receptor 41 (GPR41) $(p<0.05)$, but not with stimulation of Pattern-Recognition Receptors. Additionally, supplementation with L. reuteri 15007 in the piglets did not affect the colonic microbiota structure. Our findings suggested that L. reuteri 15007 could modulate intestinal HDP expression and improve the gut health of neonatal piglets, probably through the increase in colonic butyric acid concentration and the up-regulation of the downstream molecules of butyric acid, PPAR- $\gamma$ and GPR41, but not through modifying gut microbiota structure.
\end{abstract}

Keywords: Lactobacillus reuteri; intestinal epithelial cells; neonatal piglets; host defense peptide; gut microbiota

\section{Introduction}

On a global basis, it is estimated that 5.9 million children under the age of five years died in 2015 , most of which are caused by infectious diseases associated with bacteria that are resistant to antibiotics [1]. As key components of the innate immune system, host defense peptides (HDPs) play 
critical roles in fighting against infections for their ability of possessing antimicrobials and a low propensity for the development of bacterial resistance in younger children with immature neonatal immune systems [2,3]. HDPs have been commonly studied for their antimicrobial properties and have been shown to kill bacteria, viruses, fungi, protozoa, and even cancer cells [3]. Due to their potential therapeutic activities, HDPs are attractive candidates as alternatives for antibiotics [4]. Swine and humans share high similarity in physiologic and anatomic characteristics, which makes the former the ideal model for human health and disease $[5,6]$. In vertebrate animals, HDPs are generally grouped into two major families; defensins and cathelicidins $[7,8]$.

As an important first line of defense, HDPs are produced mainly by intestinal epithelial cells and phagocytes in the gastrointestinal tract. In addition to infection or inflammation, HDPs can also be induced by dietary compounds, including saccharides, essential amino acids, butyrate, vitamin D3, and zinc [4,9-12]. Moreover, probiotic lactobacilli could stimulate HDP expression in human cells and piglets without provoking inflammatory responses like pathogenic strains $[13,14]$. However, different lactobacilli strains show a varying magnitude of HDP-inducing activity [13].

Lactobacillus reuteri is considered to be an indigenous species in the gastrointestinal tract of humans and animals [15]. Numerous studies have demonstrated that L. reuteri has excellent probiotic properties and has been widely used as a probiotic in humans and animals [16]. L. reuteri I5007, initially known as L. fermentum I5007, was isolated from the colonic mucosa of healthy weaning piglets [17]. Compelling evidence shows that L. reuteri $\mathrm{I} 5007$ has several important probiotic properties including: (1) resistance to gastric acid and bile [18]; (2) strong adhesion [17,19]; (3) competitive exclusion against pathogens [19]; (4) alleviation of weaning stress in piglets [20]; (5) improvement of piglet performance [21,22]; (6) and positive regulation of redox status and immune function in piglets [23,24]. Notably, oral administration of L. reuteri 15007 increased the concentration of butyrate and branched chain fatty acids in the colonic digesta of suckling piglets $[22,24]$. It has been shown that butyrate, produced by butyrate-producing bacterial strains, has strong capacity to induce HDP expression in vitro. However, whether L. reuteri I5007 could modulate intestinal HDP expression through modifying gut microbiota and its metabolite butyrate in neonatal piglets is still unknown.

The aim of the current study was to investigate the effects of L. reuteri 15007 on the gut microbiota and HDP expression. We initially studied the in vitro effect of L. reuteri 15007 by inducing HDP expression in a porcine intestinal epithelial cell line. We subsequently determined the effects of L. reuteri 15007 supplementation on the colonic bacterial community and HDP expression in formula-fed neonatal piglets.

\section{Materials and Methods}

\subsection{Ethics Statement}

The procedures used in this experiment were approved by the China Agricultural University Institutional Animal Care and Use Committee (CAU20144-2, Beijing, China).

\subsection{Bacterial Strain, Growth and Storage Conditions}

L. reuteri $\mathrm{I} 5007$ was grown in De Man Rogosa Sharpe media under anaerobic conditions at $37^{\circ} \mathrm{C}$ for $20 \mathrm{~h}$. For cell culture assays, after incubation, bacterial cells were obtained by centrifugation $\left(8000 \times g\right.$ for $10 \mathrm{~min}$ at $\left.4^{\circ} \mathrm{C}\right)$. Then the bacterial cells were washed with phosphate-buffered saline (PBS, a balanced salt solution used for a variety of cell culture applications), reconstituted in DMEM/F12 (Dulbecco's Modified Eagle Medium/Nutrient Mixture F-12, 1:1 mixture of DMEM and Ham's F-12) medium supplemented with $10 \%$ fetal bovine serum (FBS) and adjusted to the required cell concentration. After centrifugation, the culture supernatant of L. reuteri I5007 was passed through a $0.2-\mu \mathrm{m}$-pore-size filter (Corning Inc., Corning, NY, USA), and it was preserved for subsequent treatment with a $10 \%(v / v)$ concentration. For heat killed bacteria, heat inactivation was carried out in a water bath at $65{ }^{\circ} \mathrm{C}$ for $1 \mathrm{~h}$. The bacterial cells were centrifugated, and the pellet was washed with 
PBS and adjusted to a density of $1 \times 10^{8}$ colony forming units (CFU) $/ \mathrm{mL}$ with DMEM/F12 medium supplemented with $10 \% \mathrm{FBS}$. The freeze-dried powder, containing $5 \times 10^{10} \mathrm{CFU} / \mathrm{g}$, was produced according to Liu et al. [22].

\subsection{Cell Culture and Treatment}

The porcine small intestinal epithelial cell line (IPEC-J2) was kindly provided by Dr. Wu at Texas A \& M University (College Station, TX, USA). IPEC-J2 cells were cultured in DMEM/F12 medium supplemented with $10 \% \mathrm{FBS}$ at $37^{\circ} \mathrm{C}$ in a $5 \% \mathrm{CO}_{2}$ and $95 \%$ air atmosphere with $90 \%$ humidity.

For stimulation experiments, undifferentiated cells were seeded at a density of $1 \times 10^{6}$ cells per well in 6-well plates (Costar, Corning Inc., Corning, NY, USA). After overnight growth (cells were grown to $\sim 80 \%$ confluence in the culture wells), the cells were treated in duplicate with L. reuteri I5007. To prevent any influence of antibiotics on the immune response, the medium did not contain antibiotics. The FBS showed no effect on expression.

For dose-dependent $L$. reuteri 15007 stimulation experiments, IPEC-J2 cells were incubated with a control or $10^{5}, 10^{6}, 10^{7}, 10^{8}$, or $10^{9} \mathrm{CFU} / \mathrm{mL}$ L. reuteri $\mathrm{I} 5007$ for $6 \mathrm{~h}$. For time-dependent $L$. reuteri 15007 stimulation experiments, IPEC-J2 cells were incubated with $10^{8} \mathrm{CFU} / \mathrm{mL}$ L. reuteri $\mathrm{I} 5007$ for 3, 6, or $12 \mathrm{~h}$.

IPEC-J2 cells were also treated for $6 \mathrm{~h}$ with $10^{8} \mathrm{CFU} / \mathrm{mL}$ L. reuteri $\mathrm{I} 5007$ exposed to different processing conditions. The processing conditions included a solvent control without $L$. reuteri $\mathrm{I} 5007$ (Control, DMEM/F12 medium supplemented with 10\% FBS), $10^{8}$ CFU/mL live L. reuteri 15007 (Live I5007), $10^{8} \mathrm{CFU} / \mathrm{mL}$ heat-killed L. reuteri $\mathrm{I} 5007$ (Dead I5007, incubated in a water bath at $65{ }^{\circ} \mathrm{C}$ for $1 \mathrm{~h}$ ), adhered L. reuteri $\mathrm{I} 5007$ (Adhered I5007, treated with $10^{8} \mathrm{CFU} / \mathrm{mL}$ L. reuteri $\mathrm{I} 5007$ for $1 \mathrm{~h}$, rinsed three times in PBS with fresh medium added, followed by continued incubation for $5 \mathrm{~h}$ ), and $200 \mu \mathrm{L}$ of $L$. reuteri I5007-free culture supernatant of L. reuteri I5007 (Supernatant, diluted 1:10 in basal medium). In addition, a Transwell Insert System (Costar, Corning Inc., Corning, NY, USA) was used to avoid direct contact between the IPEC-J2 cells and L. reuteri I5007 (Separate I5007). Herein, L. reuteri $\mathrm{I} 5007$ cells in an upper chamber and IPEC-J2 cells in a lower chamber were separated by a $0.2-\mu \mathrm{m}$-pore-size filter membrane support (Corning Inc., Corning, NY, USA), thereby minimizing any direct contact between the L. reuteri I5007 cells and IPEC-J2.

\subsection{Animals and Treatments}

The in vivo experiment was conducted in the Metabolism Laboratory of the Ministry of Agriculture Feed Industry Centre (Beijing, China). Twenty-two, full-term, crossbred (Duroc $\times$ Large White $\times$ Landrace) male piglets, obtained from six litters, were used in this study. The piglets were delivered vaginally and allowed colostrum for $48 \mathrm{~h}$ after birth. The piglets were individually housed in stainless steel cages $(1.4 \mathrm{~m} \times 0.45 \mathrm{~m} \times 0.6 \mathrm{~m})$ in a temperature $\left(32 \pm 1^{\circ} \mathrm{C}\right)$ and relative humidity $(65-70 \%)$ controlled room programmed to deliver a light:dark cycle of 16:8 h.

On the third day after parturition, the piglets were trained to suckle from bottles filled with milk replacer (Jiaduonai H001, DaChan Tianyao, Tianjin, China, Table 1), which was dissolved in warm previously boiled water $\left(45^{\circ} \mathrm{C}, w / v 1: 9\right)$. The fresh liquid milk replacer was fed to piglets individually from a feeder five times daily $(6: 00,10: 00,14: 00,18: 00$, and 22:00 h) for 20 days. After feeding, the remaining milk was measured and the feeders were cleaned before adding new fresh milk replacer. The formula did not contain any antibiotics or other medicine.

On day 4, the neonatal piglets were allocated to one of two treatments balanced for litter of origin and body weight (initial body weight of $1.81 \pm 0.31 \mathrm{~kg}$ ) with 11 piglets assigned to each treatment $(n=11)$. The treatments were comprised of a control treatment (the piglets were given a placebo of $4 \mathrm{~mL}$ of $0.1 \%$ peptone) and a L. reuteri 5007 treatment, which involved oral administration of $1.0 \times 10^{10} \mathrm{CFU}$ L. reuteri $\mathrm{I} 5007$ dissolved in $4 \mathrm{~mL}$ of $0.1 \%$ peptone water daily for 20 days.

The health status for each piglet was recorded, and the occurrence of diarrhea was assessed two times a day (monitoring time: 10 a.m. and 4 p.m.) according to the method of Marquardt et al. [25] and Ou et al. [26]. Scores were $0=$ normal, solid feces; $1=$ slight diarrhea, soft and loose feces; $2=$ moderate 
diarrhea, semi-liquid feces; or 3 = severe diarrhea, liquid and unformed feces. The occurrence of diarrhea was defined as maintaining a score of two or three for one day. The incidence of diarrhea (\%) was calculated as ((number of piglets with diarrhea $\times$ number of days of diarrhea)/(total number of experiment piglets $\times$ number of days of the whole experiment) $) \times 100 \%$.

Table 1. Composition and nutrient levels of the experimental diets (\%, as-fed basis) ${ }^{1}$.

\begin{tabular}{lc}
\hline Items & Content \\
\hline Crude protein & 24.78 \\
Gross energy $(\mathrm{MJ} / \mathrm{kg})$ & 20.46 \\
Lactose & 35.10 \\
Calcium & 0.92 \\
Total phosphorus & 0.73 \\
\hline The analyzed contents of amino acids in diets \\
\hline Asparate & 2.58 \\
Threoline & 1.72 \\
Serine & 1.35 \\
Glutamate & 4.52 \\
Proline & 1.54 \\
Glycine & 0.55 \\
Alanine & 1.30 \\
Valine & 1.48 \\
Isoleucine & 1.42 \\
Leucine & 2.54 \\
Tyrosine & 0.81 \\
Phenylalanine & 0.92 \\
Histidine & 0.52 \\
Lysine & 2.03 \\
Methonine & 0.65 \\
Argine & 0.76 \\
\hline are the means of a chemical analysis conducted in duplicates.
\end{tabular}

On days 4, 14, and 24, the piglets were weighed. On day 24, all piglets were euthanized with Zoletil $50^{\circledR}$ (Virbac, Carros, France), and all the intestinal tissues from the jejunum, ileum, and proximal distal colon were collected, frozen in liquid nitrogen, and then stored at $-80{ }^{\circ} \mathrm{C}$ until total RNA was extracted. The colonic digesta were gently squeezed into sterile Eppendorf tubes, frozen in liquid nitrogen, and subsequently stored at $-80^{\circ} \mathrm{C}$ until processing.

\subsection{Analysis of Porcine Gene Expression by Real Time PCR}

The cells and tissues (about $0.04 \mathrm{mg}$ ) were lysed directly in TRIzol (Invitrogen, Carlsbad, CA, USA). Total RNA was extracted according to the manufacturer's instructions. RNA concentrations were measured using a NanoDrop Spectrophotometer (P330, Implen, Germany). The purity was determined by the ratio of A260:A280 and A260:A230 by NanoDrop, and then the quality was checked with 1\% Agarose Gel Electrophoresis following the procedures outlined by Aranda et al. [27].

The first-strand cDNA was synthesized by reverse transcription of $1 \mu \mathrm{g}$ of total RNA using a PrimeScript 1st Strand cDNA Synthesis Kit (Takara, Dalian, China) according to the manufacturer's protocol and stored at $-80^{\circ} \mathrm{C}$. The primers used are listed in Supplemental Table S1. Porcine $\beta$-Defensin (PBD) 1, pBD2, pBD3, pBD114, pBD129, Protegrins (PG) 1-5, Epididymis Protein 2 Splicing Variant C (PEP2C), toll-like Receptors (TLR) 2, TLR4, TLR6, TLR9, Nucleotide-Binding Oligomerization Domain (NOD) 1, Mucin 1 (MUC1), Peroxisome Proliferator Activated Receptor- $\gamma$ (PPAR- $\gamma$ ) , G Protein-Coupled Receptor (GPR) 41, and GPR43 were determined [4,28-31].

Real-time PCR was performed on an Applied Biosystems 7500 Real-Time PCR System (Applied Biosystems, Singapore) using SYBR Green PCR Master Mix (Takara, Dalian, China). All reactions were run in triplicate. Relative gene expression was calculated according to the $\Delta \Delta C_{t}$ method $\left(\left(C_{t}\right.\right.$ gene of 
interest $-C_{t}$ internal control $)$ treatment $-\left(C_{t}\right.$ gene of interest $-C_{t}$ internal control $)$ control $)$ using porcine $\beta$-actin as the reference gene.

\subsection{Colonic Short Chain Fatty Acid Concentrations}

The concentrations of SCFA (short-chain fatty acid) were determined with a Dionex ICS-3000 Ion Chromatography System (Dionex Corporation, Sunnyvale, CA, USA) following the procedures of Qiu and Jin [32] with modification. Samples of colonic digesta $(0.5 \mathrm{~g})$ were weighed, diluted in a ratio of 1:5 with ultrapure water, homogenated with $8 \mathrm{~mL}$ ultrapure water, and then centrifuged at $10,000 \times g$ for $20 \mathrm{~min}$ at $4{ }^{\circ} \mathrm{C}$. The supernatant was kept in a $2 \mathrm{~mL}$ screw-capped vial. The concentrations of formic, acetic, propionic, butyric, and lactic acid were measured with the Dionex ICS-3000 Ion Chromatography System (Dionex, Sunnyvale, CA, USA).

\subsection{Fecal Microbiota Analysis}

Microbial genomic DNA was extracted and purified from colon digesta samples using a QIAmp DNA stool mini kit (Qiagen, GmbH Hilden, Germany) modified to contain a bead-beating step. Successful DNA isolation was confirmed by agarose gel electrophoresis. PCR primers flanking the V3-V4 hyper variable region of bacterial 16S rDNA were designed. The barcoded fusion forward primer was $341 \mathrm{~F}\left(5^{\prime}-\mathrm{CCTAYGGGRBGCASCAG-3}\right)$, and the reverse primer was 806R(5'-GGACTACNNGGGTATCTAAT-3'). The optimized conditions for amplification were as follows: one pre-denaturation cycle at $95{ }^{\circ} \mathrm{C}$ for $5 \mathrm{~min}, 27$ cycles of denaturation at $95{ }^{\circ} \mathrm{C}$ for $30 \mathrm{~s}$, annealing at $55{ }^{\circ} \mathrm{C}$ for $30 \mathrm{~s}$, elongation at $72{ }^{\circ} \mathrm{C}$ for $45 \mathrm{~s}$, and a final extension at $72{ }^{\circ} \mathrm{C}$ for $10 \mathrm{~min}$. The resulting amplicons were gel purified, quantified, pooled, and sequenced on the Illumina HiSeq 2500 platform. Microbiota sequences were processed through QIIME 1.8 (QIIME Team). After quality filtering, the sequences were denoised using denoise_wrapper.py. The denoised sequences were clustered into operational taxonomic units (OTUs) at a 97\% sequence similarity against the GreenGenes OTU database (gg_13_8_otus). The chimeric OTUs were removed using UCHIME v4.2. Representative sequences for each OTU were picked and aligned using QIIME 1.8. Taxon-dependent analysis was conducted using the Ribosomal Database Project (RDP) classifier. The OTUs were counted for each sample to express the richness of bacterial species with an identity cutoff of $97 \%$. Alpha and beta diversity calculations and taxonomic community assessments were performed using QIIME 1.8 scripts.

\subsection{Statistical Analysis}

Statistical analyses were performed using SPSS 17.0 Software (SPSS Inc., Chicago, IL, USA). All pairwise comparisons for the in vivo and in vitro data were examined using an unpaired Student's two-tailed $t$-test. Chi square was used to test differences in diarrhea incidence between the two groups. The level of significance was set at $p<0.05$. The results were expressed as mean \pm standard error of the mean (SEM). Principle component analysis (PCA) plots were used to visualize differences in bacterial community composition among samples. The PCA plots were produced based on a euclidean metric. Linear discriminant analysis effect size (LEfSe) analysis was used to identify the OTUs or taxa, which were responsible for the differences between the groups. An effect size threshold of two was used for the biomarkers discussed in this study. The metastats program from R-script was used to identify statistically different phylotypes among groups. Only taxa with average abundances greater than $10^{-3}$, $p<0.05$ and low $Q$ values (low risk of false discovery) were considered significant.

\section{Results}

\subsection{Effects of L. reuteri 15007 on Host Defense Peptide Expression in IPEC-J2 cells}

The mRNA expressions of porcine HDP, including pBD1, pBD2, pBD3, pBD114, pBD129, PG1-5, and pEP2C, were determined in IPEC-J2 cells to study the effects of L. reuteri 15007 on the modulation of HDP. First the dose-dependence of HDP gene expression following treatment of IPEC-J2 cells 
with L. reuteri $\mathrm{I} 5007$ was examined. Our results indicate that a $6 \mathrm{~h}$ treatment with L. reuteri $\mathrm{I} 5007$ markedly increased the mRNA expression of pBD2, pBD3, and pBD114 in a dose-dependent manner in IPEC-J2 cells, peaking at $10^{8} \mathrm{CFU} / \mathrm{mL}$ (Figure 1A). The mRNA expression levels of pBD129 and PG1-5 were also dose-dependently induced by L. reuteri $\mathrm{I} 5007$ in IPEC-J2 cells, with the maximal response occurring at $10^{9} \mathrm{CFU} / \mathrm{mL}$ (Figure 1A). However, the magnitude of induction varied obviously among the five genes, with PG1-5 showing an approximately 17-fold increase, whereas pBD3, pEP2C, and PG1-5 showed only 5-, 5-, and 7-fold induction at the peak response, respectively (Figure 1A).

An obvious time-dependent induction of pBD2, pBD3, pBD114, pBD129, and PG1-5 was also observed in IPEC-J2 cells after $10^{8} \mathrm{CFU} / \mathrm{mL}$ L. reuteri $\mathrm{I} 5007$ treatment (Figure 1B). The maximum HDP mRNA was expressed after $6 \mathrm{~h}$ of incubation and decreased at $12 \mathrm{~h}$ of incubation. It is noteworthy that pBD1 and pEP2C were largely unaltered in the IPEC-J2 cells following L. reuteri 15007 treatment.
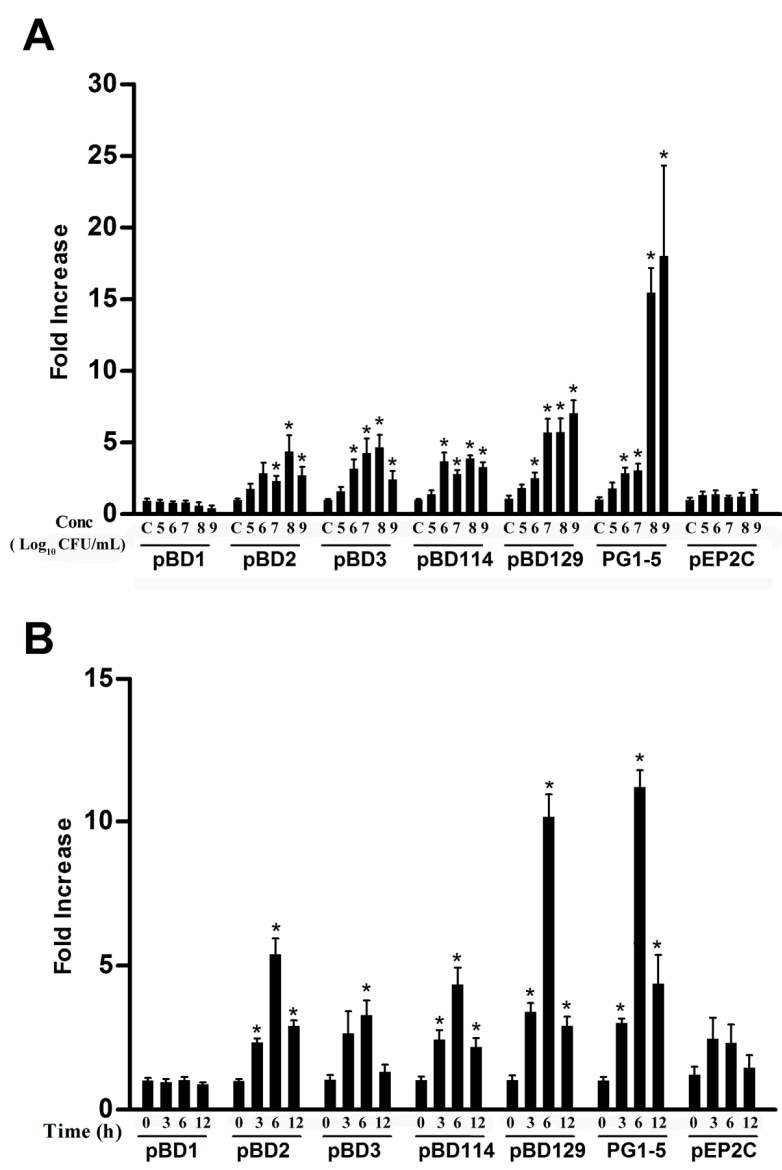

Figure 1. L. reuteri I5007-induced expression of pBD1, pBD2, pBD3, pBD114, pBD129, PG1-5, and pEP2C in porcine IPEC-J2 cells. Cells were incubated in duplicate with the indicated concentrations of (A) L. reuteri $\mathrm{I} 5007$ for $6 \mathrm{~h}$ or (B) $10^{8} \mathrm{CFU} / \mathrm{mL}$ for 3, 6, or $12 \mathrm{~h}$. Gene expression was analyzed by real-time PCR. The relative fold changes over the unstimulated control were calculated with the $\Delta \Delta C_{t}$ method using the $\beta$-actin gene for normalization. Data are mean \pm standard error obtained in three independent experiments. " $\mathrm{C}$ " in $\mathrm{X}$-axis, control group. ${ }^{*} p<0.05$ by unpaired Student's $t$-test. pBD, porcine $\beta$-Defensin; PG, protegrins; pEP2C, Epididymis Protein 2 Splicing Variant C; IPEC-J2, The porcine small intestinal epithelial cell line; $\mathrm{CFU}$, colony forming units.

3.2. Effects of Different Processing Conditions on L. reuteri 15007 Induced Host Defense Peptide Expression in IPEC-J2 Cells

To further examine whether L. reuteri 15007 induced HDP mRNA expression is altered by different processing conditions, IPEC-J2 cells were treated for $6 \mathrm{~h}$ with L. reuteri $\mathrm{I} 5007$ produced under different 
processing conditions (Figure 2). We studied whether a heat-killed strain had the ability to stimulate the expression of HDP. The results indicated that heat-killed L. reuteri 15007 was much less effective than the live strain and only stimulated pBD3 expression.

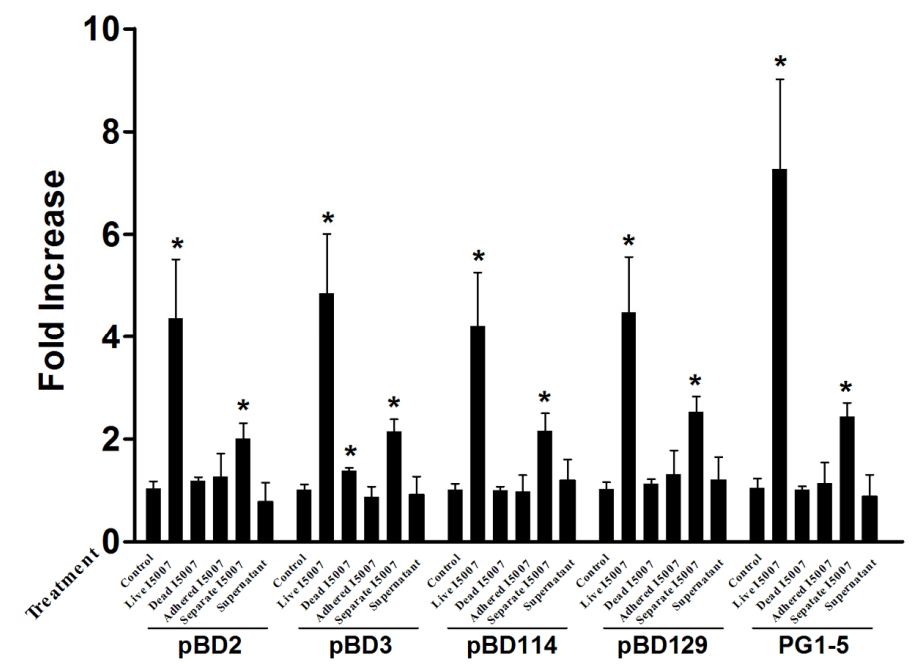

Figure 2. Regulation of pBD2, pBD3, pBD114, pBD129, and PG1-5 expression by L. reuteri 15007 subjected to different processing conditions. Porcine IPEC-J2 cells were incubated with $10^{8} \mathrm{CFU} / \mathrm{mL}$ L. reuteri 15007 (Live I5007), heat-killed L. reuteri 15007 (Dead I5007), adhered L. reuteri I5007 (Adhered I5007), L. reuteri 5007 without direct contact with IPEC-J2 (Separate I5007), culture supernatant of L. reuteri 5007 (Supernatant), and the solvent control (Control). Gene expression was analyzed by real-time PCR. The relative fold changes over the unstimulated control were calculated with the $\Delta \Delta C_{t}$ method using the $\beta$-actin gene for normalization. Data are mean \pm standard error obtained in three independent experiments. ${ }^{*} p<0.05$ by unpaired Student's $t$-test.

According to a previous study conducted in our lab, L. reuteri I5007 has strong adhesion ability to monolayer cells when co-cultured with cells for $1 \mathrm{~h}$ [14]. IPEC-J2 cells were treated with L. reuteri I5007 for $1 \mathrm{~h}$, non-adherent bacteria were washed away, and incubation continued for a further $5 \mathrm{~h}$. The results revealed that the adherent bacteria were insufficient for L. reuteri I5007-induced HDP expression.

To further examine whether cell-to-cell contact is required for L. reuteri 5007 to stimulate HDP expression in IPEC-J2 cells, a Transwell Insert System, in which the bacteria and host cells are partitioned by a $0.22-\mu \mathrm{m}$ membrane, was used to prevent all direct cell-to-cell contact between $L$. reuteri I5007 and IPEC-J2 cells. Under these conditions, L. reuteri 15007 enhanced the mRNA expression of pBD2, pBD3, pBD114, pBD129, and PG1-5 (Figure 2). These findings indicate that direct cell-to-cell contact is not required for L. reuteri $\mathrm{I} 507$ to stimulate HDP expression, and that some metabolite produced by L. reuteri 5007 may be able to cross the membrane and induce HDP expression.

To further elucidate whether the culture supernatant was involved in L. reuteri I5007 induced HDP expression, a culture supernatant of L. reuteri 15007 was also added to IPEC-J2 cells. Compared with the control group, cells treated with L. reuteri 15007 culture supernatant demonstrated no significant change in the mRNA expression of HDP. These findings indicate that there are no compounds in the culture supernatant without L. reuteri $\mathrm{I} 5007$ that stimulate HDP production in IPEC-J2 cells.

\subsection{Effects of L. reuteri 15007 on Neonatal Piglet Performance}

In this study, pigs in the two treatments (L. reuteri 15007 group and control group) started at the same age (day 4$)$ and had similar body weights $(p=0.99)$ (Table 2$)$. At the end of the experimental period (day 24), the piglets treated with L. reuteri 15007 had $15.07 \%$ higher $(p<0.05)$ average daily gain than control piglets. Moreover, the diarrhea incidence and diarrhea scores were lower in piglets 
administrated with L. reuteri 15007 compared with the control, although not significant (3.64 vs. 5.91\%, 0.12 vs. 0.20$)$.

Table 2. Effects of L. reuteri 15007 on neonatal piglet performance and diarrhea incidence ${ }^{1}$

\begin{tabular}{lllll}
\hline Items & Control & L. reuteri I5007 & SEM & $p$ Value \\
\hline Body weight at day 4 $(\mathrm{kg})$ & 1.81 & 1.81 & 0.07 & 0.99 \\
Body weight at day 14 $(\mathrm{kg})$ & 2.45 & 2.50 & 0.07 & 0.72 \\
Body weight at day 24 $(\mathrm{kg})$ & 3.72 & 4.00 & 0.10 & 0.16 \\
\hline Average daily gain $(\mathrm{g})$ & & & & \\
\hline 4-14 days & 64 & 69 & 3.91 & 0.52 \\
14-24 days & $127^{\mathrm{b}}$ & $151^{\mathrm{a}}$ & 4.86 & 0.01 \\
4-24 days & $96^{\mathrm{b}}$ & $110^{\mathrm{a}}$ & 3.31 & 0.03 \\
\hline Average feed intake $(\mathrm{g} /$ day) & & & & \\
\hline 4-14 days & 53 & 58 & 3.43 & 0.08 \\
14-24 days & 140 & 152 & 5.25 & 0.82 \\
4-24 days & 97 & 105 & 3.24 & 0.18 \\
Diarrhea score $^{2}$ & 0.20 & 0.12 & & \\
Diarrhea incidence $^{3}(\%)$ & 5.91 & 3.64 & & 0.32 \\
\hline
\end{tabular}

$a, b$ Means within a row with different superscripts are significantly different $(p<0.05) .{ }^{1}$ SEM, standard error of the mean, $n=11$ for each treatment. ${ }^{2}$ Diarrhea scores were $0=$ normal, solid feces; $1=$ slight diarrhea, soft and loose feces; 2 = definitely unformed, moderately fluid feces; or 3 = very watery and frothy diarrhea; ${ }^{3}$ The occurrence of diarrhea was defined as maintaining a score of 2 or 3 for one day. The incidence of diarrhea (\%) was calculated as ((number of piglets with diarrhea $\times$ number of days of diarrhea)/(total number of experiment piglets $\times$ number of days of the whole experiment) $) \times 100 \%$.

\subsection{Effects of L. reuteri 15007 on Host Defense Peptide Expression in Neonatal Piglets}

Twenty-two male neonatal piglets were orally administrated with $0.1 \%$ peptone solution or $1 \times 10^{10}$ CFU of $L$. reuteri 5007 daily for 20 days. The levels of mRNA expression of pBD1, pBD2, pBD3, pBD114, pBD129, PG1-5, and pEP2C in the jejunum, ileum, and colon were measured and are presented in Figure 3. Compared with the control group, no significant difference was observed in the ileal HDP expression in the L. reuteri 15007 group. Only pBD2 expression in the L. reuteri 15007 group was observed to be significantly higher than that of the control group in the jejunum. However, pBD2, pBD3, pBD114, and pBD129 mRNA expression were significantly up-regulated in the colon of piglets administrated with L. reuteri 15007 compared with the control piglets.

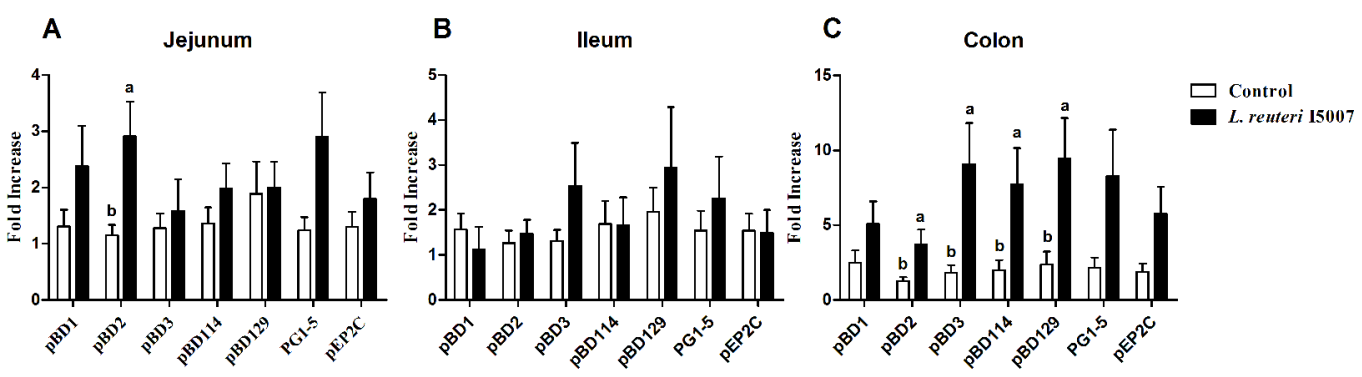

Figure 3. Regulation of pBD1, pBD2, pBD3, pBD114, pBD129, PG1-5, and pEP2C expression by L. reuteri I5007 in the (A) jejunum, (B) ileum, and (C) colon of neonatal piglets. Twenty-two male neonatal piglets were orally administrated with $0.1 \%$ peptone solution (control) or $1 \times 10^{10} \mathrm{CFU}$ of L. reuteri I5007 daily for 20 days. Gene expression was analyzed by real-time PCR. The relative fold changes over the control were calculated with the $\Delta \Delta C_{t}$ method using the $\beta$-actin gene for normalization. White bars or black bars represent control or L. reuteri I5007 treatments, respectively. Values are presented as mean \pm standard error of the mean, $n=11$ piglets per treatment. Bars with different letters differ, $p<0.05$ by unpaired Student's $t$-test. 


\subsection{Effects of L. reuteri 15007 on Short Chain Fatty Acid Concentrations in Colonic Digesta}

The concentrations of SCFA in colonic digesta are presented in Table 3. The concentration of butyric acid was higher in piglets treated with L. reuteri 15007 compared with the control group $(p<0.05)$. The concentration of formic acid tended to be higher in L. reuteri 15007 treated piglets $(p=0.08)$, while the acetic, propionic, and lactic acid concentrations did not differ between the two treatments.

Table 3. Effects of L. reuteri 15007 on short chain fatty acid concentrations (mmol $/ \mathrm{kg}$, wet weight) in colonic digesta obtained from neonatal piglets ${ }^{1}$.

\begin{tabular}{ccccc}
\hline Fatty acid & Control & L. reuteri I5007 & SEM & $p$ Value \\
\hline Formic acid & 0.03 & 0.03 & 0.01 & 0.66 \\
Acetic acid & 32.49 & 37.74 & 2.03 & 0.20 \\
Propionic acid & 12.99 & 15.90 & 0.83 & 0.08 \\
Butyric acid & $7.10^{\mathrm{b}}$ & $9.51^{\mathrm{a}}$ & 0.58 & 0.04 \\
Lactic acid & 3.67 & 3.66 & 0.35 & 1.00 \\
\hline
\end{tabular}

a,b Means within a row with different superscripts are significantly different $(p<0.05) .{ }^{1}$ SEM, standard error of the mean, $n=11$ for each treatment. Means within a row with different superscripts are significantly different $(p<0.05)$.

\subsection{Effects of L. reuteri I5007 on PPAR- $\gamma$, GPR41 and GPR43 in Colonic Tissue}

The relative transcription levels of PPAR- $\gamma$, GPR41, and GPR43 in the colonic tissue were analyzed using real-time PCR (Figure 4). The relative abundances of mRNA for PPAR- $\gamma$ and GPR41 were significantly increased in the colonic tissue of piglets treated with L. reuteri $\mathrm{I} 5007$ compared with the control treatment $(p<0.05)$.

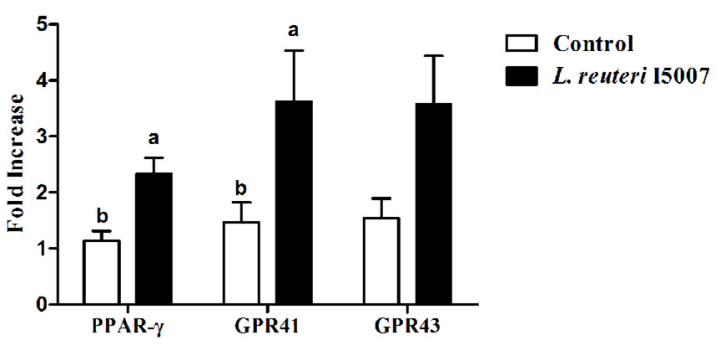

Figure 4. Effects of L. reuteri I5007 on PPAR- $\gamma$, GPR41, and GPR43 expression in the colonic tissue of neonatal piglets. Gene expression was analyzed by real-time PCR. The relative fold changes over the control were calculated with the $\Delta \Delta \mathrm{C}_{\mathrm{t}}$ method using the $\beta$-actin gene for normalization. Data are mean \pm standard error $(n=11)$. Bars with different letters differ, $p<0.05$ by unpaired Student's $t$-test.

\subsection{Effects of L. reuteri 15007 on Bacterial Community Structure in Colonic Digesta}

A total of 810,187 high quality sequences were obtained from all fecal samples, with an average of 36,826 sequences per sample. These sequences were assigned to 680 operational taxonomic units (OTUs). The Shannon diversity indices reached stable values, suggesting that the present study captured the dominant phylotypes. The fecal samples of all of the pigs were dominated by four phyla; Bacteroidetes, Firmicutes, Spirochaetes, and Proteobacteria, with Firmicutes and Bacteroidetes accounting for $>95 \%$ of the bacteria (Figure 5A). The abundance of Firmicutes (76.69 \pm 3.16 vs. $69.41 \pm 3.46 ; p=0.13$, $Q=0.87)$ and Bacteroidetes (18.26 \pm 3.04 vs. $25.81 \pm 3.63 ; p=0.13, Q=0.87$ ) was not significantly different between groups (Supplemental Table S2). An analysis of colonic microbiota composition by principal component analysis revealed that $L$. reuteri $\mathrm{I} 5007$ administration did not affect the overall composition of the fecal microbiota (Supplemental Figure S1). No significant differences were observed in relative abundance of bacterial taxa or operational taxonomic units between placebo-treated and L. reuteri-treated piglets except that three bacterial taxa were identified by LEfSe analysis (linear 
discriminant analysis, LDA score $>2$ ) (Figure 5B). These significant differences were further confirmed by metastats analysis, in which genera Sharpea were significantly increased in L. reuteri 15007 group ( $p=0.03$ and 0.02 , respectively) (Supplemental Table S2). To determine whether the difference in colonic butyrate concentration was caused by the alteration of genera Sharpea, the correlation between the butyrate level and Sharpea was analyzed. However, no significant correlation was found between the butyrate level and genera Sharpea $(r=0.05, p=0.82$, Spearman).

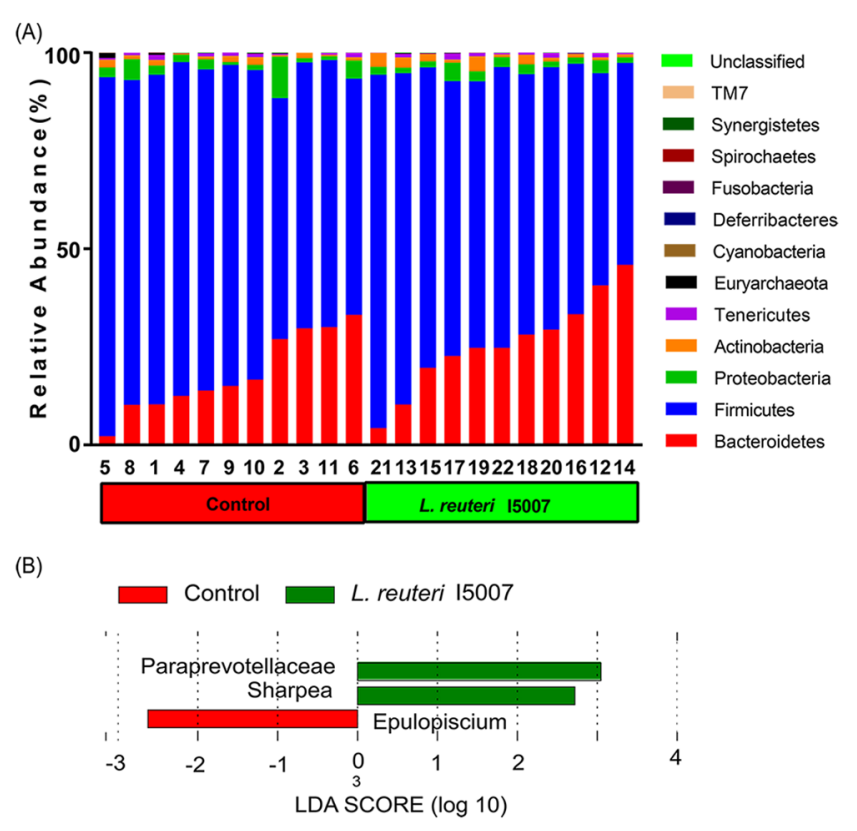

Figure 5. Effects of L. reuteri 15007 on bacterial community structure in colonic digesta. (A) Relative abundance levels of the bacterial phyla present in control group and L. reuteri 15007 group; (B) Histogram of the LDA scores computed for taxa differentially abundant between control and L. reuteri $\mathrm{I} 5007$ treated piglets $(n=11)$.

\subsection{Effects of L. reuteri I5007 on Pattern-Recognition Receptor (PRRs) Expression in Intestinal Tissue}

An analysis of PRRs by real-time PCR revealed that the expressions of TLR2, TLR4, TLR6, TLR9, and NOD1 were not changed with L. reuteri 15007 treatment in the jejunum, ileum, or colon $(p>0.05)$. The relative abundance of mRNA for MUC1 was significantly increased in the colon with L. reuteri I5007 treatment compared with the control treatment $(p<0.05)$, while no significant differences were observed in the jejunum and ileum (Supplemental Figure S2).

\section{Discussion}

In the present study, we observed that the probiotic L. reuteri 15007 induced the expression of HDP in a porcine small intestinal epithelial cell line (IPEC-J2). In addition, we observed that oral administration of L. reuteri $\mathrm{I} 5007$ stimulated colonic HDP expression in neonatal piglets. Finally, we found that $L$. reuteri 15007 increased concentrations of butyric acid in neonatal piglets but did not affect the colonic bacterial community structure.

Probiotics have been shown to induce $\beta$-Defensin (hBD-2) in human cells, and different probiotic strains show different HDP-inducing activity [13]. In pigs, L. salivarius can induce pBD2 production in the digestive tract [14]. L. reuteri is one of dominant species in the gastrointestinal tracts of humans and animals and is currently used as a probiotic in pigs [16]. Oral administration of L. reuteri modulates ileum microbial composition, intestinal development, and immune status in pigs [22,24]. However, there are no reports of the effects of L. reuteri on the stimulation of HDP gene expression in IPEC-J2 cells and pigs. 
Previous studies have indicated that pBD1, pBD2, pBD3, pBD114, pBD129, PG1-5, and pEP2C are expressed in IPEC-J2 cells [4]. In this study, we found that L. reuteri 15007 administration increased pBD2, pBD3, pBD114, pBD129, and PG1-5 gene expression in these same cells. The time-dependent experiments showed a similar pattern, as previously described by Wehkamp et al. [33] and Schlee et al. [13], with the maximum level of HDP being induced after $6 \mathrm{~h}$ of incubation. The dose-dependent experiment showed that L. reuteri 5007 induced HDP production when the concentration of L. reuteri $\mathrm{I} 5007$ reached $10^{6} \mathrm{CFU} / \mathrm{mL}$.

Previously, Schlee et al. [13] used heat-killed bacteria, but we decided to research the effects of live strains. Since $L$. reuteri $\mathrm{I} 5007$ is used as a probiotic, the results for live strains may be helpful for future in vivo studies. Wehkamp et al. [33] also found a living form of E. coli Nissle 1917, which showed a strong induction of hBD-2 after incubation with Caco-2 cells for $4.5 \mathrm{~h}$. A previous study demonstrated that heat-killed bacteria induced hBD-2 [13], but we found that only pBD3 expression was significantly increased with heat killed L. reuteri in the present study. Compared with the live strain, the capacity of the heat-killed L. reuteri 15007 to induce HDP was visibly diminished.

The suspension without bacteria did not induce HDP, which is consistent with the findings described by Wehkamp et al. [33] for E. coli Nissle 1917. In order to determine whether L. reuteri I5007 induced HDP by cell-to-cell contact, a Transwell Insert System was used. Our results indicate that L. reuteri I5007 without contact with IPEC-J2 cells also induced HDP, which suggests that a metabolite produced by L. reuteri $\mathrm{I} 507$ may be playing a role.

Neonatal piglets have an immature immune system, are susceptible to infections, and often suffer from diarrhea and growth retardation if infected [4]. Our previous studies showed that the optimum dosage (about $10^{10} \mathrm{CFU} /$ day of L. reuteri I5007) could improve performance and reduce diarrhea incidence in neonatal piglets [22]. In this study, we obtained a similar result. We also found that the administration of $L$. reuteri 15007 induced pBD2 in the jejunum and pBD2, pBD3, pBD114, and pBD129 in the colon. Similar results have been obtained for L. salivarius induced expression of pBD2 in the pig jejunum [14]. The spatial heterogeneity patterns of this induction effect were probably due to the production of butyric acid, mainly triggered in the hindgut after L. reuteri I5007 administration [34]. It has been reported that most of the porcine HDP (e.g., pBD1, pBD2, pBD114, pBD129, PG1-5, pEP2C) show various activity against Gram-negative and Gram-positive bacteria, including Salmonella typhimurium, Escherichia coli, and Clostridium perfringen, the blooms of which are involved in the occurrence of diarrhea [35,36]. In addition to its antimicrobial properties, pBD3 could also regulate the expression of IL-8 and intestinal tight junction protein and exhibits a strong immunoregulatory ability [37]. In addition, $\beta$-defensins (hBD2) have been observed to have the capacity to recruit leukocytes. These actions can directly modify the inflammatory response [38]. The induction of the expression of HDP genes allows the immature intestinal epithelial surfaces of neonatal piglets to cope with these continuously complex microbial challenges [38]. Furthermore, previous studies showed that the supplementation of synthetic HDP could improve nutrient digestibility, intestinal morphology, and growth performance in weanling pigs [39] and broiler chickens [40]. These results suggest that the induction of HDP gene expression by L. reuteri 15007 may be responsible for the body weight increase and decrease in diarrhea incidence, which was mostly caused by the bloom of pathogens that can be eliminated by the HDPs [35,41,42].

Short chain fatty acids are the major metabolites of microbial digestion in the colon and have been considered as contributing an important role in normal colonic morphology and function [34]. Recent published data have proven that HDP could be induced by SCFA, especially by butyrate [4]. Our previous work and that of others indicated that administration of probiotics increased butyrate levels in the colonic digesta and fecal samples [22,24]. In this experiment, after the administration of L. reuteri $\mathbf{5 0 0 7}$, the quantity of butyric acid in the colonic digesta was increased, which is consistent with the finding of Liu et al. [22] and may be the mechanism through which L. reuteri 15007 induces the expression of HDP. 
Exposure to SCFA, such as butyrate, triggers profound changes in epithelial gene expression in vitro [43,44], which are mediated at least in part through the SCFA sensor PPAR- $\gamma$ [45]. GPR41 (Free Fatty Acid Receptor 3, FFA3) and GPR43 (FFA2) are related G Protein-Coupled Receptors that are activated by short chain carboxylic acids [46,47]. In order to further confirm the changes of SCFA, we determined the changes of short-chain fatty acid receptors in the colon. PPAR- $\gamma$ and GPR41 were observed to be higher in mRNA expression after L. reuteri I5007 administration compared with piglets in the control treatment.

Changes in the structure of gut microbiota alter the gut-microbial metabolism and eventually influence intestinal mucosal immunity and host metabolism [48,49]. Previous studies have reported increases of lactic acid bacteria after the intake of individual lactobacilli strains [50-53]. The administration of Lactobacillus rhamnosus GG increases the fecal butyrate level through expanding butyrate-producing bacterial strains [54]. To examine whether the significant difference in butyrate concentration of colonic digesta was induced by the change of microbiota structure after L. reuteri I5007 administration, the colonic microbial community was determined. Unexpectedly, the results of the next generation high throughput sequencing showed no significant changes in the colonic microbiota composition or stability, which was consistent with our previous finding using polymerase chain reaction (PCR)-denaturing gradient gel electrophoresis (DGGE) profiling [22]. Similar observations have been reported in a recent review [55], suggesting that probiotics do not significantly modify the gut microbiota composition of healthy subjects. Additionally, microbiomes were compared at different taxonomic levels, and no differences were detected except the specific increase of genera Sharpea, which is a member of Clostridium XVII and exhibits a close phylogenetic association with Lactobacillus catenaformis and Lactobacillus vitulinus [56]. However, no significant correlation was found between the butyrate level and genera Sharpea, which indicated that the increase of butyrate levels was not due to the alteration of genera Sharpea. It has recently been reported that the introduction of probiotics significantly changes the microbiome's transcriptional profile but has no significant impact on the structure, leading us to speculate that L. reuteri I5007 may increase the butyrate concentration through modulating the microbial metabolic activities. Taken together, these results suggest that L. reuteri 15007 might increase butyrate levels through modulating the microbiota at the transcript level, rather than modifying the bacterial community structure in the colonic digesta $[57,58]$. PRRs could recognize conserved molecular motifs present on a wide range of different microbes, which have been termed Microbe-Associated Molecular Patterns (MAMPs). TLRs and NOD proteins are two classes of PRRs involved in innate immune detection [59]. Agreeing with the result of colonic bacterial community analysis, the mRNA levels for PRRs were unaffected by L. reuteri 5007 treatment, which indicated that $L$. reuteri 5007 induction of HDP expression was not induced through regulating the structure of the colonic bacterial community or expression of PRRs $[57,58,60]$.

\section{Conclusions}

In conclusion, our study indicates that $L$. reuteri 15007 could regulate the expression of pBD2, pBD3, pBD114, pBD129, and PG1-5 in IPEC-J2 cells and stimulate the mRNA expression of colonic pBD2, pBD3, pBD114, and pBD129 in the neonatal piglets, which is probably mediated by increased butyric acid production and the up-regulation of the downstream molecules of butyric acid, PPAR- $\gamma$ and GPR41, but not by modulation of the colonic microbial community. These findings suggest that the probiotic $L$. reuteri 15007 enhances HDP expression, which strengthens the mucosal antimicrobial barrier of neonatal piglets and is one explanation for the growth promoting effect of L. reuteri I5007. The identification of $L$. reuteri $I 5007$ with favorable odors will expedite its application as a non-antibiotic, immune boosting additive for infectious disease prevention and control in pigs and other animal species; perhaps human beings as well.

Supplementary Materials: The following are available online at http://www.mdpi.com/2072-6643/9/6/559/s1. Figure S1: Effects of L. reuteri 15007 on bacterial community structure in colonic digesta, Figure S2: Effects of L. reuteri 15007 on TLR2, TLR4, TLR6, TLR9, NOD1, and Muc1 expression in the (A) jejunum, (B) ileum, 
and (C) colon of neonatal piglets, Table S1: Primer sequences used in the study, Table S2: Effect of L. reuteri I5007 on the relative abundance (\%) of bacterial groups at the phylum, family, and genus level (above $1 \%$ abundance in at least one sample) detected in colonic digesta microbiota of piglets $(n=11)$.

Acknowledgments: This work was supported by the National Natural Science Foundation of China (Grant Number 31420103908).

Author Contributions: H.L., C.H., and S.Q. conceived and designed the experiments; H.L., C.H., G.W., H.J., and H.Y. performed the experiments; H.L., X.Z., and C.H. analyzed the data and wrote the paper; and H.J. contributed reagents/materials/analysis tools.

Conflicts of Interest: The authors declare no conflict of interest.

\section{Abbreviations}

HDP, host defense peptide; pBD, porcine $\beta$-defensin; PPAR- $\gamma$, peroxisome proliferator-activated receptor- $\gamma$; GPR, G protein-coupled receptor; SCFAs, short chain fatty acids; LDA, linear discriminant analysis; CFU, colony forming units; PRRs, pattern-recognition receptors; $\mathrm{pEP} 2 \mathrm{C}$, porcine epididymis protein 2 splicing variant C; PG, cysteine-rich protegrins; TLR, toll-like receptor; NOD, nucleotide-binding oligomerization domain; MUC, Mucin.

\section{References}

1. Laxminarayan, R.; Matsoso, P.; Pant, S.; Brower, C.; Rottingen, J.A.; Klugman, K.; Davies, S. Access to effective antimicrobials: A worldwide challenge. Lancet 2016, 387, 168-175. [CrossRef]

2. Nijnik, A.; Hancock, R. Host defence peptides: Antimicrobial and immunomodulatory activity and potential applications for tackling antibiotic-resistant infections. Emerg. Health Threats J. 2009, 2, e1. [CrossRef] [PubMed]

3. Hancock, R.E.; Sahl, H.G. Antimicrobial and host-defense peptides as new anti-infective therapeutic strategies. Nat. Biotechnol. 2006, 24, 1551-1557. [CrossRef] [PubMed]

4. Zeng, X.; Sunkara, L.T.; Jiang, W.; Bible, M.; Carter, S.; Ma, X.; Qiao, S.; Zhang, G. Induction of porcine host defense peptide gene expression by short-chain fatty acids and their analogs. PLoS ONE 2013, 8, e72922. [CrossRef] [PubMed]

5. Gonzalez, L.M.; Williamson, I.; Piedrahita, J.A.; Blikslager, A.T.; Magness, S.T. Cell lineage identification and stem cell culture in a porcine model for the study of intestinal epithelial regeneration. PLoS ONE 2013, 8, e66465. [CrossRef] [PubMed]

6. Meurens, F.; Summerfield, A.; Nauwynck, H.; Saif, L.; Gerdts, V. The pig: A model for human infectious diseases. Trends Microbiol. 2012, 20, 50-57. [CrossRef] [PubMed]

7. Selsted, M.E.; Ouellette, A.J. Mammalian defensins in the antimicrobial immune response. Nat. Immunol. 2005, 6, 551-557. [CrossRef] [PubMed]

8. Zanetti, M. Cathelicidins, multifunctional peptides of the innate immunity. J. Leukoc. Biol. 2004, 75, 39-48. [CrossRef] [PubMed]

9. Talukder, P.; Satho, T.; Irie, K.; Sharmin, T.; Hamady, D.; Nakashima, Y.; Kashige, N.; Miake, F. Trace metal zinc stimulates secretion of antimicrobial peptide LL-37 from Caco-2 cells through ERK and p38 MAP kinase. Int. Immunopharmacol. 2011, 11, 141-144. [CrossRef] [PubMed]

10. Fehlbaum, P.; Rao, M.; Zasloff, M.; Anderson, G.M. An essential amino acid induces epithelial beta -defensin expression. Proc. Natl. Acad. Sci. USA 2000, 97, 12723-12728. [CrossRef] [PubMed]

11. Cederlund, A.; Kai-Larsen, Y.; Printz, G.; Yoshio, H.; Alvelius, G.; Lagercrantz, H.; Stromberg, R.; Jornvall, H.; Gudmundsson, G.H.; Agerberth, B.; et al. Lactose in human breast milk an inducer of innate immunity with implications for a role in intestinal homeostasis. PLoS ONE 2013, 8, e53876. [CrossRef] [PubMed]

12. Gombart, A.F.; Borregaard, N.; Koeffler, H.P. Human cathelicidin antimicrobial peptide (CAMP) gene is a direct target of the vitamin $\mathrm{D}$ receptor and is strongly up-regulated in myeloid cells by 1,25-dihydroxyvitamin D3. FASEB J. 2005, 19, 1067-1077. [CrossRef] [PubMed]

13. Schlee, M.; Harder, J.; Koten, B.; Stange, E.F.; Wehkamp, J.; Fellermann, K. Probiotic lactobacilli and VSL\#3 induce enterocyte beta-defensin 2. Clin. Exp. Immunol. 2008, 151, 528-535. [PubMed]

14. Zhang, J.; Deng, J.; Li, Y.; Yang, Q. The effect of Lactobacillus on the expression of porcine $\beta$-defensin-2 in the digestive tract of piglets. Livest. Sci. 2011, 138, 259-265. [CrossRef] 
15. Valeur, N.; Engel, P.; Carbajal, N.; Connolly, E.; Ladefoged, K. Colonization and immunomodulation by Lactobacillus reuteri ATCC 55730 in the human gastrointestinal tract. Appl. Environ. Microbiol. 2004, 70, 1176-1181. [CrossRef] [PubMed]

16. Hou, C.; Zeng, X.; Yang, F.; Liu, H.; Qiao, S. Study and use of the probiotic Lactobacillus reuteri in pigs: A review. J. Anim. Sci. Biotechnol. 2015, 6, 14. [CrossRef] [PubMed]

17. Hou, C.; Wang, Q.; Zeng, X.; Yang, F.; Zhang, J.; Liu, H.; Ma, X.; Qiao, S. Complete genome sequence of Lactobacillus reuteri I5007, a probiotic strain isolated from healthy piglet. J. Biotechnol. 2014, 179, 63-64. [CrossRef] [PubMed]

18. Huang, C.; Qiao, S.; Li, D.; Piao, X.; Ren, J. Effects of lactobacilli on the performance, diarrhea incidence, VFA concentration and gastrointestinal microbial flora of weaning pigs. Asian Australas. J. Anim. Sci. 2004, 17, 401-409. [CrossRef]

19. Li, X.J.; Yue, L.Y.; Guan, X.F.; Qiao, S.Y. The adhesion of putative probiotic lactobacilli to cultured epithelial cells and porcine intestinal mucus. J. Appl. Microbiol. 2008, 104, 1082-1091. [CrossRef] [PubMed]

20. Wang, X.; Yang, F.; Liu, C.; Zhou, H.; Wu, G.; Qiao, S.; Li, D.; Wang, J. Dietary Supplementation with the Probiotic Lactobacillus fermentum 5007 and the Antibiotic Aureomycin Differentially Affects the Small Intestinal Proteomes of Weanling Piglets. J. Nutr. 2011, 142, 7-13. [CrossRef] [PubMed]

21. Yu, H.F.; Wang, A.N.; Li, X.J.; Qiao, S.Y. Effect of viable Lactobacillus fermentum on the growth performance, nutrient digestibility and immunity of weaned pigs. J. Anim. Feed Sci. 2008, 17, 61-69. [CrossRef]

22. Liu, H.; Zhang, J.; Zhang, S.; Yang, F.; Thacker, P.A.; Zhang, G.; Qiao, S.; Ma, X. Oral administration of Lactobacillus fermentum 15007 favors intestinal development and alters the intestinal microbiota in formula-fed piglets. J. Agric. Food Chem. 2014, 62, 860-866. [CrossRef] [PubMed]

23. Wang, A.N.; Cai, C.J.; Zeng, X.F.; Zhang, F.R.; Zhang, G.L.; Thacker, P.A.; Wang, J.J.; Qiao, S.Y. Dietary supplementation with. J. Appl. Microbiol. 2013, 114, 1582-1591. [CrossRef] [PubMed]

24. Hou, C.; Liu, H.; Zhang, J.; Zhang, S.; Yang, F.; Zeng, X.; Thacker, P.; Zhang, G.; Qiao, S. Intestinal Microbiota Succession and Immunomodulatory Consequences after Introduction of Lactobacillus reuteri 15007 in Neonatal Piglets. PLoS ONE 2015, 10, e0119505. [CrossRef] [PubMed]

25. Marquardt, R.R.; Jin, L.Z.; Kim, J.W.; Fang, L.; Frohlich, A.A.; Baidoo, S.K. Passive protective effect of egg-yolk antibodies against enterotoxigenic Escherichia coli K88+ infection in neonatal and early-weaned piglets. FEMS Immunol. Med. Microbiol. 1999, 23, 283-288. [CrossRef] [PubMed]

26. Ou, D.; Li, D.; Cao, Y.; Li, X.; Yin, J.; Qiao, S.; Wu, G. Dietary supplementation with zinc oxide decreases expression of the stem cell factor in the small intestine of weanling pigs. J. Nutr. Biochem. 2007, 18, 820-826. [CrossRef] [PubMed]

27. Aranda, P.S.; LaJoie, D.M.; Jorcyk, C.L. Bleach gel: A simple agarose gel for analyzing RNA quality. Electrophoresis 2012, 33, 366-369. [CrossRef] [PubMed]

28. Arce, C.; Ramirez-Boo, M.; Lucena, C.; Garrido, J.J. Innate immune activation of swine intestinal epithelial cell lines (IPEC-J2 and IPI-2I) in response to LPS from Salmonella typhimurium. Comp. Immunol. Microbiol. Infect. Dis. 2010, 33, 161-174. [CrossRef] [PubMed]

29. Li, B.; Zerby, H.N.; Lee, K. Heart fatty acid binding protein is upregulated during porcine adipocyte development. J. Anim. Sci. 2007, 85, 1651-1659. [CrossRef] [PubMed]

30. Li, G.; Su, H.; Zhou, Z.; Yao, W. Identification of the porcine G protein-coupled receptor 41 and 43 genes and their expression pattern in different tissues and development stages. PloS ONE 2014, 9, e97342. [CrossRef] [PubMed]

31. Mariani, V.; Palermo, S.; Fiorentini, S.; Lanubile, A.; Giuffra, E. Gene expression study of two widely used pig intestinal epithelial cell lines: IPEC-J2 and IPI-2I. Vet. Immunol. Immunopathol. 2009, 131, 278-284. [CrossRef] [PubMed]

32. Qiu, J.; Jin, X. Development and optimization of organic acid analysis in tobacco with ion chromatography and suppressed conductivity detection. J. Chromatogr. A 2002, 950, 81-88. [CrossRef]

33. Wehkamp, J.; Harder, J.; Wehkamp, K.; Wehkamp-von Meissner, B.; Schlee, M.; Enders, C.; Sonnenborn, U.; Nuding, S.; Bengmark, S.; Fellermann, K.; et al. NF-kB-and AP-1-mediated induction of human beta defensin-2 in intestinal epithelial cells by Escherichia coli Nissle 1917: A novel effect of a probiotic bacterium. Infect. Immun. 2004, 72, 5750-5758. [CrossRef] [PubMed]

34. Topping, D.L.; Clifton, P.M. Short-chain fatty acids and human colonic function: Roles of resistant starch and nonstarch polysaccharides. Physiol. Rev. 2001, 81, 1031-1064. [PubMed] 
35. Weber, N.; Nielsen, J.P.; Jakobsen, A.S.; Pedersen, L.L.; Hansen, C.F.; Pedersen, K.S. Occurrence of diarrhoea and intestinal pathogens in non-medicated nursery pigs. Acta Vet. Scand. 2015, 57, 64. [CrossRef] [PubMed]

36. Sang, Y.; Blecha, F. Porcine host defense peptides: Expanding repertoire and functions. Dev. Comp. Immunol. 2009, 33, 334-343. [CrossRef] [PubMed]

37. Dou, X.; Han, J.; Song, W.; Dong, N.; Xu, X.; Zhang, W.; Shan, A. Sodium butyrate improves porcine host defense peptide expression and relieves the inflammatory response upon Toll-like receptor 2 activation and histone deacetylase inhibition in porcine kidney cells. Oncotarget 2017, 8, 26532-26551. [CrossRef] [PubMed]

38. Gallo, R.L.; Hooper, L.V. Epithelial antimicrobial defence of the skin and intestine. Nat. Rev. Immunol. 2012, 12, 503-516. [CrossRef] [PubMed]

39. Yoon, J.H.; Ingale, S.L.; Kim, J.S.; Kim, K.H.; Lohakare, J.; Park, Y.K.; Kwon, I.K.; Chae, B.J. Effects of dietary supplementation with antimicrobial peptide-P5 on growth performance, apparent total tract digestibility, faecal and intestinal microflora and intestinal morphology of weanling pigs. J. Sci. Food Agric. 2013, 93, 587-592. [CrossRef] [PubMed]

40. Wen, L.F.; He, J.G. Dose-response effects of an antimicrobial peptide, a cecropin hybrid, on growth performance, nutrient utilisation, bacterial counts in the digesta and intestinal morphology in broilers. Br. J. Nutr. 2012, 108, 1756-1763. [CrossRef] [PubMed]

41. Cullen, T.W.; Schofield, W.B.; Barry, N.A.; Putnam, E.E.; Rundell, E.A.; Trent, M.S.; Degnan, P.H.; Booth, C.J.; $\mathrm{Yu}$, H.; Goodman, A.L. Gut microbiota. Antimicrobial peptide resistance mediates resilience of prominent gut commensals during inflammation. Science 2015, 347, 170-175. [CrossRef] [PubMed]

42. Goyette-Desjardins, G.; Auger, J.P.; Xu, J.; Segura, M.; Gottschalk, M. Streptococcus suis, an important pig pathogen and emerging zoonotic agent-an update on the worldwide distribution based on serotyping and sequence typing. Emerg. Microbes. Infect. 2014, 3, e45. [CrossRef] [PubMed]

43. Basson, M.D.; Liu, Y.; Hanly, A.M.; Emenaker, N.J.; Shenoy, S.G.; Rothberg, B.E.G. Identification and comparative analysis of human colonocyte short-chain fatty acid response genes. J. Gastrointest. Surg. 2000, 4, 501-512. [CrossRef]

44. Sanderson, I.R. Short chain fatty acid regulation of signaling genes expressed by the intestinal epithelium. J. Nutr. 2004, 134, 2450S-2454S. [PubMed]

45. Alex, S.; Lange, K.; Amolo, T.; Grinstead, J.S.; Haakonsson, A.K.; Szalowska, E.; Koppen, A.; Mudde, K.; Haenen, D.; Roelofsen, H.; et al. Short-chain fatty acids stimulate angiopoietin-like 4 synthesis in human colon adenocarcinoma cells by activating peroxisome proliferator-activated receptor $\gamma$. Mol. Cell. Biol. 2013, 33, 1303-1316. [CrossRef] [PubMed]

46. Brown, A.J.; Goldsworthy, S.M.; Barnes, A.A.; Eilert, M.M.; Tcheang, L.; Daniels, D.; Muir, A.I.; Wigglesworth, M.J.; Kinghorn, I.; Fraser, N.J. The Orphan G protein-coupled receptors GPR41 and GPR43 are activated by propionate and other short chain carboxylic acids. J. Biol. Chem. 2003, 278, 11312-11319. [CrossRef] [PubMed]

47. Tazoe, H.; Otomo, Y.; Kaji, I.; Tanaka, R.; Karaki, S.I.; Kuwahara, A. Roles of short-chain fatty acids receptors, GPR41 and GPR43 on colonic functions. J. Physiol. Pharmacol. 2008, 59 (Suppl. 2), 251-262. [PubMed]

48. Leser, T.D.; Mølbak, L. Better living through microbial action: The benefits of the mammalian gastrointestinal microbiota on the host. Environ. Microbiol. 2009, 11, 2194-2206. [CrossRef] [PubMed]

49. Lopez, C.A.; Kingsbury, D.D.; Velazquez, E.M.; Baumler, A.J. Collateral damage: Microbiota-derived metabolites and immune function in the antibiotic era. Cell Host Microbe 2014, 16, 156-163. [CrossRef] [PubMed]

50. Savard, P.; Lamarche, B.; Paradis, M.E.; Thiboutot, H.; Laurin, E.; Roy, D. Impact of Bifidobacterium animalis subsp. lactis BB-12 and, Lactobacillus acidophilus LA-5-containing yoghurt, on fecal bacterial counts of healthy adults. Int. J. Food Microbiol. 2011, 149, 50-57. [CrossRef] [PubMed]

51. Yamano, T.; Iino, H.; Takada, M.; Blum, S.; Rochat, F.; Fukushima, Y. Improvement of the human intestinal flora by ingestion of the probiotic strain Lactobacillus johnsonii La1. Br. J. Nutr. 2006, 95, 303-312. [CrossRef] [PubMed]

52. Lahti, L.; Salonen, A.; Kekkonen, R.A.; Salojärvi, J.; Jalanka-Tuovinen, J.; Palva, A.; Orešič, M.; de Vos, W.M. Associations between the human intestinal microbiota, Lactobacillus rhamnosus GG and serum lipids indicated by integrated analysis of high-throughput profiling data. PeerJ 2013, 1, e32. [CrossRef] [PubMed] 
53. Rajkumar, H.; Kumar, M.; Das, N.; Kumar, S.N.; Challa, H.R.; Nagpal, R. Effect of Probiotic Lactobacillus salivarius UBL S22 and Prebiotic Fructo-oligosaccharide on Serum Lipids, Inflammatory Markers, Insulin Sensitivity, and Gut Bacteria in Healthy Young Volunteers: A Randomized Controlled Single-Blind Pilot Study. J. Cardiovasc. Pharmacol. Ther. 2015, 20, 289-298. [CrossRef] [PubMed]

54. Berni, C.R.; Sangwan, N.; Stefka, A.T.; Nocerino, R.; Paparo, L.; Aitoro, R.; Calignano, A.; Khan, A.A.; Gilbert, J.A.; Nagler, C.R. Lactobacillus rhamnosus GG-supplemented formula expands butyrate-producing bacterial strains in food allergic infants. ISME J. 2015, 10, 742-750.

55. Kristensen, N.B.; Bryrup, T.; Allin, K.H.; Nielsen, T.; Hansen, T.H.; Pedersen, O. Alterations in fecal microbiota composition by probiotic supplementation in healthy adults: A systematic review of randomized controlled trials. Genome. Med. 2016, 8, 52. [CrossRef] [PubMed]

56. Morita, H.; Shiratori, C.; Murakami, M.; Takami, H.; Toh, H.; Kato, Y.; Nakajima, F.; Takagi, M.; Akita, H.; Masaoka, T.; et al. Sharpea azabuensis gen. nov., sp. nov., a Gram-positive, strictly anaerobic bacterium isolated from the faeces of thoroughbred horses. Int. J. Syst. Evol. Microbiol. 2008, 58, 2682-2686. [CrossRef] [PubMed]

57. Eloe-Fadrosh, E.A.; Brady, A.; Crabtree, J.; Drabek, E.F.; Ma, B.; Mahurkar, A.; Ravel, J.; Haverkamp, M.; Fiorino, A.M.; Botelho, C.; et al. Functional dynamics of the gut microbiome in elderly people during probiotic consumption. MBio 2015, 6. [CrossRef] [PubMed]

58. McNulty, N.P.; Yatsunenko, T.; Hsiao, A.; Faith, J.J.; Muegge, B.D.; Goodman, A.L.; Henrissat, B.; Oozeer, R.; Cools-Portier, S.; Gobert, G.; et al. The Impact of a Consortium of Fermented Milk Strains on the Gut Microbiome of Gnotobiotic Mice and Monozygotic Twins. Sci. Transl. Med. 2011, 3, 106ra106. [CrossRef] [PubMed]

59. Chu, H.; Mazmanian, S.K. Innate immune recognition of the microbiota promotes host-microbial symbiosis. Nat. Immunol. 2013, 14, 668-675. [CrossRef] [PubMed]

60. Turroni, F.; Milani, C.; Duranti, S.; Mancabelli, L.; Mangifesta, M.; Viappiani, A.; Lugli, G.A.; Ferrario, C.; Gioiosa, L.; Ferrarini, A.; et al. Deciphering bifidobacterial-mediated metabolic interactions and their impact on gut microbiota by a multi-omics approach. ISME J. 2016, 10, 1656-1668. [CrossRef] [PubMed]

(C) 2017 by the authors. Licensee MDPI, Basel, Switzerland. This article is an open access article distributed under the terms and conditions of the Creative Commons Attribution (CC BY) license (http:/ / creativecommons.org/licenses/by/4.0/). 